\title{
Prospection et étude d'impact 1991
}

Ariège et Haute Garonne

\section{(2) OpenEdition \\ Journals}

Édition électronique

URL : http://journals.openedition.org/adlfi/10747

ISSN : 2114-0502

Éditeur

Ministère de la culture

\section{Référence électronique}

"Prospection et étude d'impact 1991 », ADLFI. Archéologie de la France - Informations [En ligne], Midi-

Pyrénées, mis en ligne le 01 mars 1997, consulté le 02 mai 2019. URL : http:// journals.openedition.org/adlfi/10747

Ce document a été généré automatiquement le 2 mai 2019.

(c) Ministère de la Culture et de la Communication, CNRS 


\title{
Prospection et étude d'impact 1991
}

\author{
Ariège et Haute Garonne
}

\section{Identifiant de l'opération archéologique :}

Date de l'opération : 1991 (PR)

Inventeur(s) : Vidal Charles

1 Un projet d'autoroute entre Pamiers (Ariège) et Toulouse (Haute-Garonne) a nécessité la mise en place d'une étude d'impact préliminaire afin d'évaluer la potentialité archéologique d'un secteur devant être perturbé,à moyen terme, par des travaux autoroutiers. Cet état des connaissances est lié, dans un premier temps, à l'étude de la bibliographie existante, de la géologie, de la toponymie et précède une prospection systématique au sol sur l'emprise du futur tracé (une bande de $300 \mathrm{~m}$ de large).

2 Sur le plan géologique, nous nous trouvons en présence des coteaux molassiques du Laurageais et dans la plaine alluviale de Pamiers. De fait, la formation naturelle d'un réseau important de drainage qui entraîne la formation de thalweg ou de fortes sédimentations provoquant alluvionnement et colluvionnement, explique la rareté des sites préhistoriques et protohistoriques recouverts par ces épaisseurs de sédiments.

Plus de cent trente sites (toutes époques confondues) ont été répertoriés. Ils confirment, pour leur plus grande part, des connaissances issues de publications anciennes et surtout récentes portant sur l'occupation du sol (Baby, 1981; Baccrabère, 1963 et 1983). Les résultats déjà acquis ne méritent donc pas que l'on s'y attache et convient-il tout au plus de mettre en évidence les gisements jusqu'alors inédits ou mal connus.

\section{Département de l'Ariège}

4 Pour la préhistoire, des sites du Paléolithique et du Néolithique ont été repérés à Pamiers, colline de Rambaud et à la Caserne; à Saverdun, Borde-Grande et Les Peries. Dans ce dernier site, la préhistoire était associée à une occupation protohistorique mal représentée quantitativement comme au Vernet-d'Ariège, Bois Peyrat (éperon barré?). 
5 Les établissements gallo-romains sont nombreux: Pamiers, Riveneuve-du-Bosc, Villeneuve-du-Paréage, le Cimetière; Montaut, Gaillardot; Saverdun, La Barthale, Roudelle. Plusieurs édifices du Haut Moyen Âge sont encore mis en évidence, par exemple à Mazères, LaBourdette, alors qu'à l'époque médiévale se rattachent plusieurs autres gisements tels ceux de Pamiers, Vignoble de Salvetotte, Houmatel, Bois-l'Évêque ; Bonnac, Le Freyche (église Saint-Jean) ;Vernet-d'Ariège, Saint-Paul (église Saint-Sevrin) ; Montaut, Pégulier (motte castrale), Counils; Saverdun, Saint-Pierre (église Saint-Martin), Baulias, etc., ainsi que plusieurs châteaux d'époque moderne. Enfin, des structures quadrangulaires (Pamiers, Rivière-le-Neuf; Saverdun, Vigné-Bas) ou circulaires (Mazères, Prouille et La Grangeotte) décelées par photographies aériennes sont difficiles à interpréter (enclos?).

\section{Département de la Haute-Garonne}

Les perturbations d'ordre géologique mises en évidence précédemment n'ont permis de localiser qu'un seul gisement néolithique sur la commune d'Aignes, La Grange.

7 L'époque gallo-romaine est dominante avec des établissements signalés à:Calmont, Montplaisir; Gibel, Janicot;Saint-Léon, Saint-Roch; Vieillevigne, Le Cammas; Montesquieu-Lauragais, Jammes, Boissonnade, En Semy, EnSelve ; avec quelques édifices du Haut Moyen Âge : Saint-Léon, Saint-Roch ;Montesquieu-Lauragais, le Cimetière (église Saint-Jean) et les Peluts (église Saint-Pierre), etc.

Le Moyen Âge est surtout représenté par des lieux de culte :Calmont, La Garenne et SaintSernin ; Gibel, Gabatchous, Villefer, Coulom ; Montgeard, La Petite Bourdette ; Gardouch, le Cimetière (chapelle Saint-Gabelin), etc. Ici aussi, la photo-interprétation faite à partir des clichés de l'IGN a été à l'origine de la découverte de plusieurs structures quadrangulaires (Calmont, Le Roussel ; Monestrol, Garrabbet ; Montesquieu-Lauragais, Le Fort, Poncet) ou circulaires (Calmont, Cussolet, Chyne, Palancade ; Monestrol, Garrabet ; Nailloux, En Fiol) dont la destination et la chronologie restent imprécises. En revanche, une structure rectangulaire ouverte entourant une structure carrée à Gibel, La Tuilerie peut s'apparenter à un fanum (?), alors que de petits enclos associés à des silos, à Vieillevigne, Clos-de-la-Fontet à Montesquieu-Lauragais, En Courail, peuvent correspondre, par ailleurs, à des habitats médiévaux.

\section{INDEX}

Index chronologique : âge du Fer, Antiquité romaine, Moyen Âge**, Néolithique, Paléolithique, Temps Modernes

operation Prospection (PR) 